\title{
Pain Controlling and Cytokine-regulating Effects of Lyprinol, a Lipid Extract of Perna Canaliculus, in a Rat Adjuvant-induced Arthritis Model
}

\author{
Chi-Ho Lee ${ }^{1}$, John Hon-Kei Lum ${ }^{1}$, Curtise Kin-Cheung Ng${ }^{2}$, Janice McKay ${ }^{2}$, \\ Yoki Kwok-Chu Butt ${ }^{1}$, Man-Sau Wong ${ }^{1}$ and Samuel Chun-Lap Lo ${ }^{1}$ \\ ${ }^{1}$ State Key Laboratory of Chinese Medicine and Molecular Pharmacology, Shenzhen and Department of Applied \\ Biology and Chemical Technology and ${ }^{2}$ Department of Health Technology and Informatics, Hong Kong Polytechnic \\ University, Hung Hom, Kowloon, Hong Kong SAR, China
}

\begin{abstract}
Using an adjuvant-induced arthritis rat model, we investigated the effects of a lipid extract of Perna canaliculus (Lyprinol $^{\circledR}$ ) on pain. Radiological examinations, as well as levels of pro- and anti-inflammatory (AI) cytokines, were measured aiming to provide independent objective data to the pain controlling investigation. We confirmed the ability of Lyprinol ${ }^{\circledR}$ to control pain at the initial phase of its administration; with similar efficacy to that observed with Naproxen. The pain scores slowly increased again in the group of rats treated with Lyprinol ${ }^{\circledR}$ after day 9-14. The Naproxen-treated rats remained pain-free while treated. Both Naproxen and Lyprinol ${ }^{\circledR}$ decreased the levels of the pro-inflammatory cytokines TNF- $\alpha$ and IFN- $\gamma$, and increased that of IL-10. Extra-virgin olive oil was ineffective on cytokine secretion. Rats treated with Lyprinol ${ }^{\circledR}$ were apparently cured after 1 year. This study confirms the AI efficacy of this lipid extract of $P$. canaliculus, its initial analgesic effect, its perfect tolerance and its long-term healing properties.
\end{abstract}

Keywords: adjuvant-induced arthritis - inflammatory cytokines - Lyprinol ${ }^{\circledR}$ - NZGLM, pain score

\section{Introduction}

\section{Lipid Extract of New Zealand Green-lipped Mussel} $\left(\right.$ Lyprinol $^{\circledR}$ )

A lipid-rich and stabilized extract of New Zealand greenlipped mussel Perna canaliculus powder (NZGLM, Lyprinol ${ }^{\circledR}$ ), has been shown to have significant antiinflammatory (AI) activity when given to animals and humans (1-11). This article contributes to the emerging literature on bioprospecting (12). This approach seeks to emphasize for complementary and alternative medicine (CAM) the utility of products derived from animals in treating certain diseases (13-17). Lyprinol ${ }^{\circledR}$ is a mixture

For reprints and all correspondence: Prof. Samuel C. L. Lo, Dept. of Applied Biology \& Chemical Technology, The Hong Kong Polytechnic University, Hung Hom, Kowloon, Hong Kong SAR, China. of five main lipid classes including sterol esters, triglycerides, free fatty acids, sterols and polar lipids $(18,19)$. There are 90 component fatty acids in Lyprinol ${ }^{\circledR}(18,19)$. Omega-3 polyunsaturated fatty acids are one of the most abundant PUFAs. Eicosapentaenoic acid (20 carbons and 5 double bonds, shorthand $=20: 5$ omega-3) (EPA) and docosahexaenoic acid (22: 6 omega-3) (DHA) are the major omega-3 PUFAs present in Lyprinol.

\section{Anti-inflammatory Effects}

Although the exact active ingredients that brought about this AI effect are unknown, Whitehouse et al. (3) reported that Wistar and Dark Agouti rats treated p.o. with this lipid extract did not develop adjuvant-induced polyarthritis or collagen (II)-induced auto-allergic arthritis. This was achieved with doses inferior to the ones 
of NSAIDs, and 200 times lower than other seed or fish oils (3). Further, omega-3 PUFA subfractions of this lipid extract inhibited $\mathrm{LTB}_{4}$ biosynthesis by neutrophils in vitro, and $\mathrm{PGE}_{2}$ production by activated macrophages (20). Subfractions of this extract containing natural antioxidants (e.g. carotenoids) also exhibited AI activity (5). In contrast to NSAIDs, Lyprinol ${ }^{\circledR}$ is non-gastro-toxic in disease-stressed rats at $300 \mathrm{mg} \mathrm{kg}^{-1}$ p.o. (3), and does not affect platelet aggregation in both humans and rats (3).

Clinical studies, either controlled or randomized, have demonstrated that Lyprinol ${ }^{\circledR}$ has highly significant AI activity in patients with osteoarthritis (OA) $(4,7,8,21)$, asthma (22) and other inflammatory conditions (10). Therefore, it seems that Lyprinol $^{\circledR}$ is a reproducible, stable source of bioactive lipids with much greater potency than plant/marine oils currently used as nutritional supplements to ameliorate signs of inflammation $(3,10,23)$. More importantly, in humans and animal subjects taking Lyprinol ${ }^{\circledR}$, there are no reported sideeffects, even at doses up to $2500 \mathrm{mg}$ per day in patients.

Given the AI activities of Lyprinol ${ }^{\mathbb{R}}$, we were interested to know if these AI effects could be translated into paincontrolling effects. We conducted a series of experiments to understand the AI mechanism of action of this lipid extract. This article reports our findings on the pain scores and the accepted causes of pain in rats subjected to severe arthritis induced by adjuvant. In comparison to extra-virgin olive oil (vehicle/negative control) and to the NSAID Naproxen (positive control), we confirmed the pain-controlling ability of Lyprinol ${ }^{\circledR}$ at the initial phase of its administration. This ability is similar to the one observed with Naproxen. Cytokine levels in/from splenocytes of these animals, as well as radiological examination of the affected joints, were also measured to bring objective confirmation to the pain controlling investigation.

\section{Methods}

\section{Chemicals}

Unless stated otherwise, all chemicals were purchased from Sigma (St Louis, MO, USA). All chemicals were at least of AR grade. Organic solvents used were at least of HPLC grade.

\section{Induction of Inflammation in Sprague-Dawley Rats}

Four groups of six 6-week-old male SpragueDawley (SD) rats (normal group, adjuvant-induced arthritis (AIA) group, AIA + Naproxen group and AIA + Lyprinol group) and two groups of three 6-week old SD rats (AIA group and AIA + long-term Lyprinol feeding group, respectively) were purchased from the
Central Animal Facility (CAF) of Hong Kong Polytechnic University (HKPU). All rats were kept and cared under conditions that fully met requirements of Procedures for the Care of Laboratory Animals or Animals (Control of Experiments) Regulations Chapter 340 of the Hong Kong SAR government. Ethics approval (ASESC No.04/9) was from The Animal Subjects Ethics subcommittee of the HKPU. Arthritis was induced in anesthetized rats by administration of adjuvant according to a method previously described $(24,25)$. Briefly, on Day 0 , each rat was injected into the paw of the right hind limb with $100 \mu 1$ of Freund's complete adjuvant containing $10 \mathrm{mg} \mathrm{m}^{-1}$ of Mycobacterium butyricum (Difco, Livonia, MI, USA). Another six rats without arthritis induction were observed as a normal group.

\section{Products/Drug Tested Fed to the Treatment and Control Groups of Rats}

Rats in the Lyprinol ${ }^{\circledR}$ (Pharmalink International Ltd, Burleigh Heads, QLD, Australia) group were fed by oral gavage at a dosage of $25 \mathrm{mg}$ Lyprinol $\mathrm{kg}^{-1}$ body weight. Typically, the required amount of Lyprinol was made up with olive oil (Virgin ${ }^{\circledR}$, Bertolli, Italy) to $300 \mu$ and then force-fed to the rats with a stainless steel stomach tube. Three hundred micro liters of olive oil, and $20 \mathrm{mg} \mathrm{kg}^{-1}$ body weight of Naproxen were fed as vehicle and positive control. Normal chow was provided to all rats. Except for the long-term Lyprinol-feeding group, feeding of Lyprinol, olive oil and Naproxen were discontinued after the experimental period of 28 days. For the long-term Lyprinol-feeding group, the required amount of diluted Lyprinol (to a dosage of $25 \mathrm{mg} \mathrm{kg}^{-1}$ body weight) was added onto $25 \mathrm{~g}$ of dry rat chow. These chows were fed to rats daily. Once these chows were completely consumed, normal chows were given.

\section{Pain Score Measurement}

The measurement of pain score was performed according to Hayashida et al. (26). The number of pain-related responses, represented by vocalizations, was recorded during 10 flexions of the tarsotibial joints of the adjuvant-injected paw. Results were expressed as the mean number of vocalizations.

\section{Splenocyte Preparation}

At Day 14 and 28 after arthritis induction, splenocytes of each rat of group $P$. canaliculus, Naproxen, olive oil and control were prepared as described previously (27). Briefly, spleens were removed aseptically and minced into tiny pieces. Single cell suspensions were prepared by gentle grinding of spleen pieces in RPMI 1640 medium (Life Technologies, US). Splenocytes (mostly B- and 
T-cells) from the crude spleen cell suspension were recovered by using Ficoll-Hypaque ${ }^{\circledR}$ Plus lymphocyte isolation kit (Pharmacia Biotech, USA) as described in the manufacturer's manual. Recovered splenocytes $(1.5 \mathrm{ml})$ were transferred into a sterile centrifuge tube and four volumes of pre-chilled $0.83 \%$ ammonium chloride $\left(\mathrm{NH}_{4} \mathrm{Cl}\right)$ was added and incubated for $10 \mathrm{~min}$ for lysis of residual erythrocytes (28). Splenocytes were recovered by centrifugation at $3000 \mathrm{rpm}$ for $5 \mathrm{~min}$, washed with $8 \mathrm{ml}$ pre-warmed $\left(37^{\circ} \mathrm{C}\right)$ sterile PBS buffer $\left(137 \mathrm{mM} \mathrm{NaCl}, 2.7 \mathrm{mM} \mathrm{KCl}, 4.3 \mathrm{mM} \mathrm{Na} \mathrm{HPO}_{4} 7 \mathrm{H}_{2} \mathrm{O}\right.$, $1.4 \mathrm{mM} \mathrm{KH} \mathrm{KHO}_{4}, \mathrm{pH} 7.4$ ) and finally resuspended in appropriate volume of complete RPMI 1640 medium $\left(10 \%\right.$ fetal bovine serum, 100 units $\mathrm{ml}^{-1}$ of penicillin and $100 \mu \mathrm{g} \mathrm{ml}^{-1}$ of streptomycin, supplemented with $0.3 \mathrm{mg} / \mathrm{ml} \mathrm{L}$-glutamine and $25 \mathrm{mM}$ HEPES).

\section{Cell Count and Viability Staining}

Resuspended splenocytes were stained with $0.4 \%$ Trypan blue exclusion dye $(0.4 \mathrm{~g}$ Trypan blue in $100 \mathrm{ml}$ PBS buffer) at ratio 1: 1. Number of splenocytes was counted and calculated with the aid of a hemocytometer. More than $99 \%$ of splenocytes were viable. Except stated otherwise, splenocytes were diluted to a working popula-

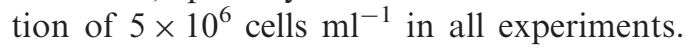

\section{ELISA Assay for Cytokines}

A total of $5 \times 10^{6}$ splenocytes $\mathrm{ml}^{-1}$ were seeded in 24-well plate; a suboptimal concentration $\left(1.25 \mu \mathrm{g} \mathrm{m}^{-1}\right)$ of lipopolysaccharide (LPS) (Sigma, St Louis, MO, USA) was used to prime the splenocyte culture. Splenocytes were incubated in $37^{\circ} \mathrm{C}$ incubator with $80 \%$ humidity and $5 \% \mathrm{CO}_{2}$ atmosphere condition. Supernatant was collected at 10 and $24 \mathrm{~h}$ after LPS activation and stored at $-80^{\circ} \mathrm{C}$ until later measurement. Interleukin-10 (IL-10), tumor necrosis factor-alpha (TNF- $\alpha)$ and interferongamma (IFN- $\gamma$ ) were measured by enzyme-liked immunosorbent assay (ELISA) (BioSource, CA, USA) as described in the user's manual.

\section{Statistical Analysis}

Experimental data were compared to the ones of the control group and analyzed by Student's $t$-test with one way ANOVA.

\section{Results}

\section{Photographic and Radiographic Analysis of AIA Rat Paws}

Figure 1 shows photographs of the right hind paw of rat at different times after AIA induction. Figure 1A was taken at 14 days after AIA induction. Swelling of the whole right hind paw, especially around the tarsotibial
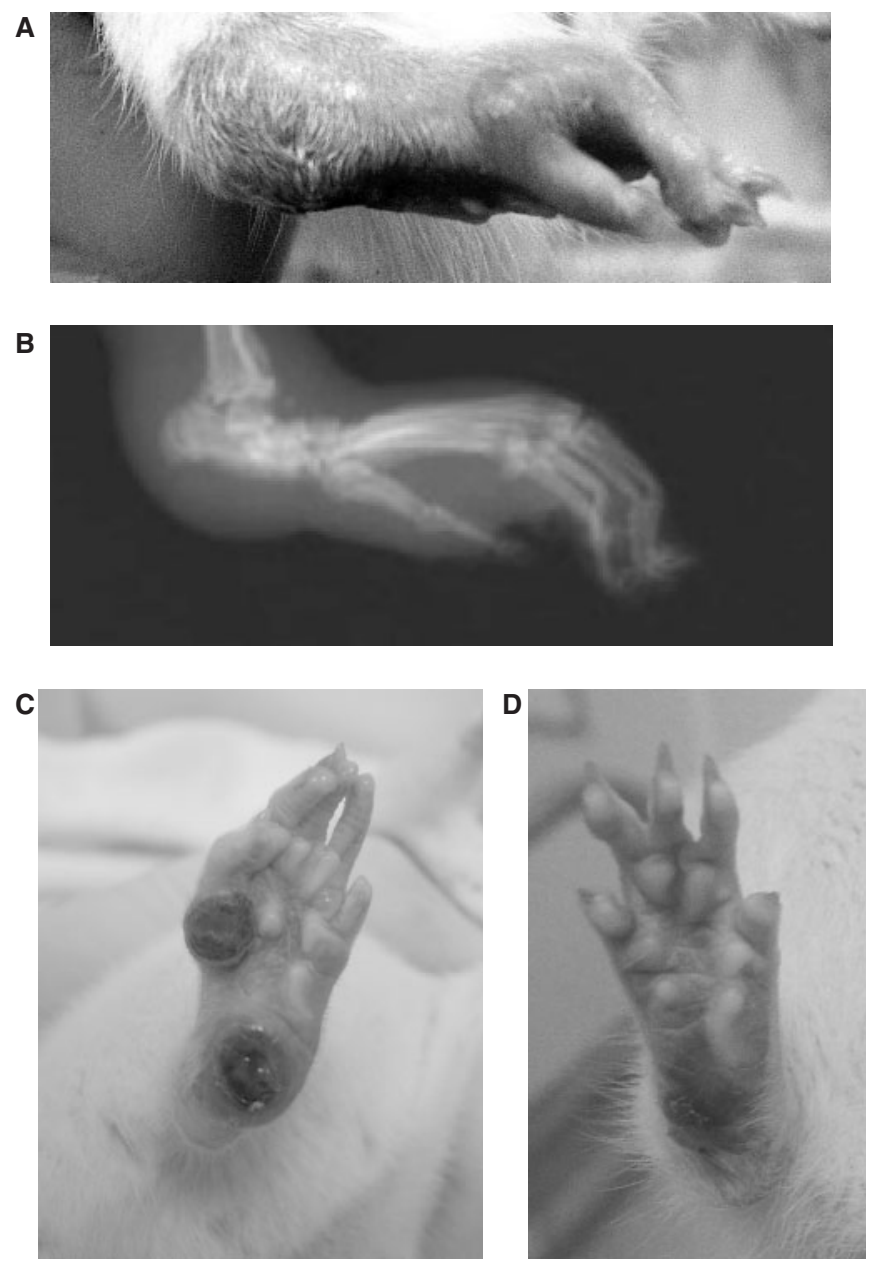

Figure 1. Photographic and radiographic analysis of adjuvant-induced arthritis (AIA) rats. (A) Photograph of the right hind paw taken 14 days after AIA induction. Swelling and inflammation of the paws were observed, especially around the ankle region. (B) Radiographic analysis of the same right hind paw at Day 21 after AIA induction. Note the swelling of soft tissues as well as bone deformation around the ankle region. (C) Photograph of the right hind paw in one of the representative rats in the olive oil group at 1 year after AIA induction. Toes and footpad are deformed, with multiple lesions. (D) However, rats fed with Lyprinol ${ }^{\circledR}$-for 1 year recovered much better. Photograph of the right hind paw in one of the representative rats in the Lyprinol ${ }^{\circledR}$ treatment group showed only mild joint deformation and no lesion.

joints, is significant as shown in the photo. X-ray photography of the same paw at Day 21 after AIA reveals severe periarticular soft tissue swelling, joint subluxation and periostal new bone formation (Fig. 1B). The degree of arthritis between control group and Lyprinol $^{\circledR}$ group shows no difference during the whole 28-day course of the experiment. However, 1 year after the induction of AIA, deformation of joints and lesions are still observable in the olive oil-control group (Fig. 1C). Conversely, deformation of joints and lesions are not visible in the Lyprinol $^{\circledR}$-long-term treatment group (Fig. 1D). 


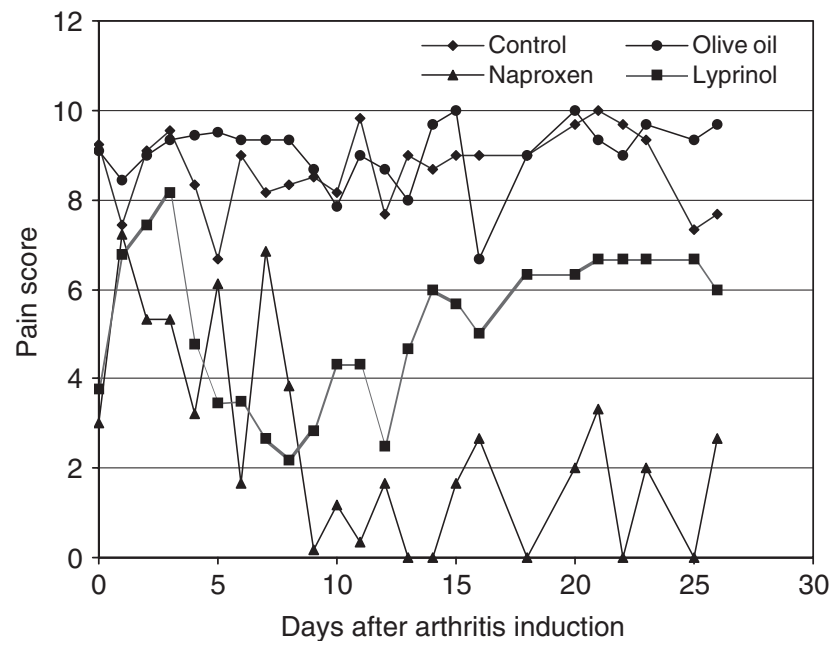

Figure 2. Mean pain score measured by 10 flexions of the tarsotibial joints of adjuvant-injected paw $(n=6)$, as described in Methods. Note that Lyprinol $^{\circledR}$ effectively controlled pain between Day 4 and Day 12 when compared to control and olive oil groups.

\section{Pain Score Measurement}

Pain score measurement is a widely used and reliable method to reflect the effectiveness of different treatments on AIA (26). It is one of the commonly used methodologies to measure level of pain $(29,30,31)$. As shown in Fig. 2, the NSAID Naproxen effectively maintained the pain score of AIA rats at a relatively low level during the whole course of the experiment. Compared to the ones of the control and olive oiltreated groups, Lyprinol $^{\circledR}$ effectively lowered the pain score of AIA rats from Day 4 to Day 26 after induction of arthritis. The effect of Lyprinol $^{\circledR}$ was most pronounced between Day 4 and Day 12, with an effect comparable to that of Naproxen. The effect of Lyprinol ${ }^{\circledR}$ began to wane after Day 14, but still maintained the pain score at a significantly lowered level when compared to the control and olive oil-treated groups. Our results clearly demonstrated that Lyprinol $^{\circledR}$ is very useful in controlling pain of severe arthritis, especially during the early and intermediate phase of AIA.

\section{Level of Pro-inflammatory Cytokines Tumor Necrosis Factor-alpha and interferon-gamma}

At Day 14 after induction of arthritis, splenocytes from Lyprinol ${ }^{\circledR}$-fed rats were harvested and pro-inflammation cytokines levels were determined. As shown in Fig. 3, TNF- $\alpha$ level of Lyprinol ${ }^{\circledR}$ group was greatly decreased from $3.07 \pm 0.168$ to $1.71 \pm 0.405 \mathrm{ng} \mathrm{ml}^{-1}$. Besides, production of another pro-inflammatory cytokine, IFN- $\gamma$, was significantly decreased. As shown in Fig. 4, the IFN- $\gamma$ level of the Lyprinol ${ }^{\circledR}$ group, when compared to control, was dramatically decreased from level $10.7 \pm 0.8$ to $3.0 \pm 0.9 \mathrm{ng} \mathrm{ml}^{-1}$.

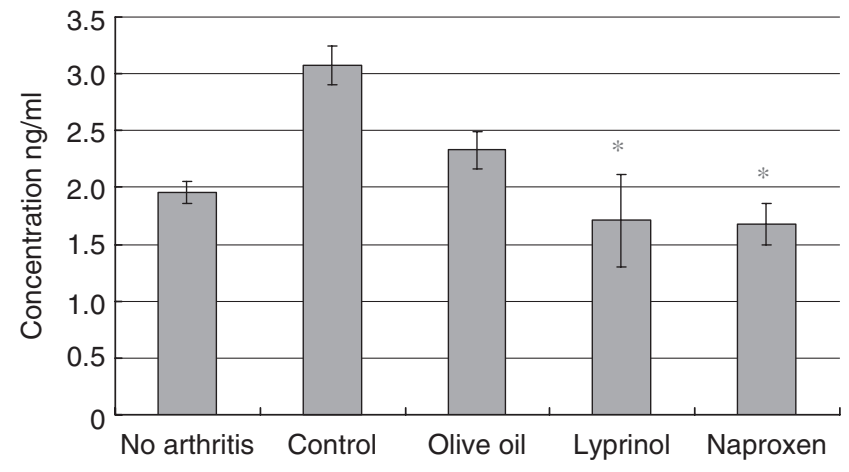

Figure 3. Amount of tumor necrosis factor-alpha (TNF- $\alpha$ ) produced by LPS-stimulated splenocytes 14 days after arthritis induction. Lyprinol ${ }^{\circledR}$ controlled the amount of TNF- $\alpha$ production to a level similar to the one found in rats with no arthritis, and was as effective as the NSAID Naproxen. Values shown here are mean $\pm \operatorname{SEM}(n=6) .{ }^{*} P<0.05$.

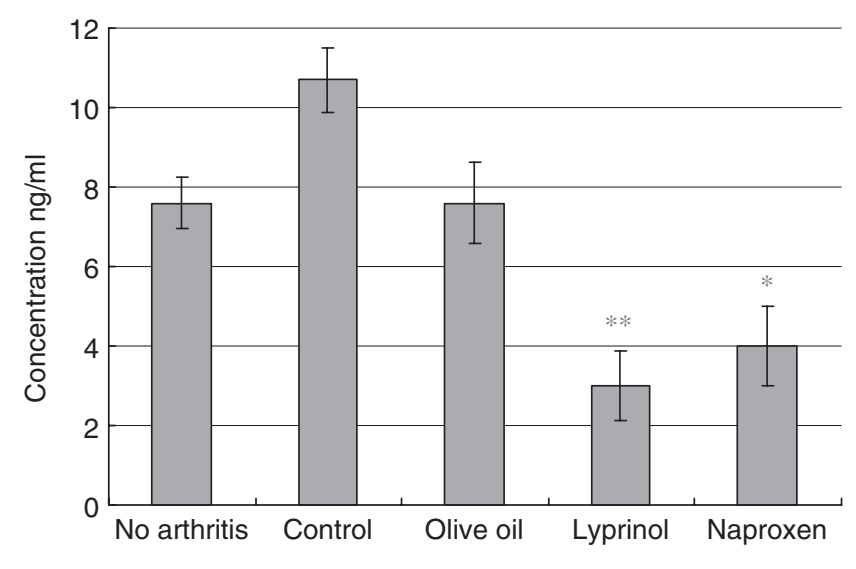

Figure 4. Amount of interferon-gamma (IFN- $\gamma$ ) produced by LPS-stimulated splenocytes 14 days after arthritis induction. Lyprinol ${ }^{\circledR}$ effectively reduced the amount of IFN- $\gamma$ produced, when compared to control and olive oil groups. Strikingly, Lyprinol ${ }^{\circledR}$ was even more potent than the NSAID Naproxen in controlling the IFN- $\gamma$ level. Values shown are mean $\pm \operatorname{SEM}(n=6)$. ${ }^{*} P<0.05 ; * * P<0.001$.

\section{Level of Anti-inflammatory Cytokine Interleukin-10}

Figure 5 shows that the AI cytokine IL-10 increased at Day 28 after AIA. Although there is no statistically significant difference between the levels observed in the control group and the Lyprinol ${ }^{\circledR}$ group, the increase of IL-10 in the Lyprinol ${ }^{\circledR}$ group almost reached levels observed in the positive control group (Naproxen).

\section{Discussion}

Pain score measurement is a widely used and reliable method to reflect the effectiveness of different treatments on AIA (26). It is one of the commonly used methodologies to measure level of pain. AIA in the rat is a standard model accepted for the study of inflammation and its control by medications or supplements (32). We used this model in order to get a better understanding 


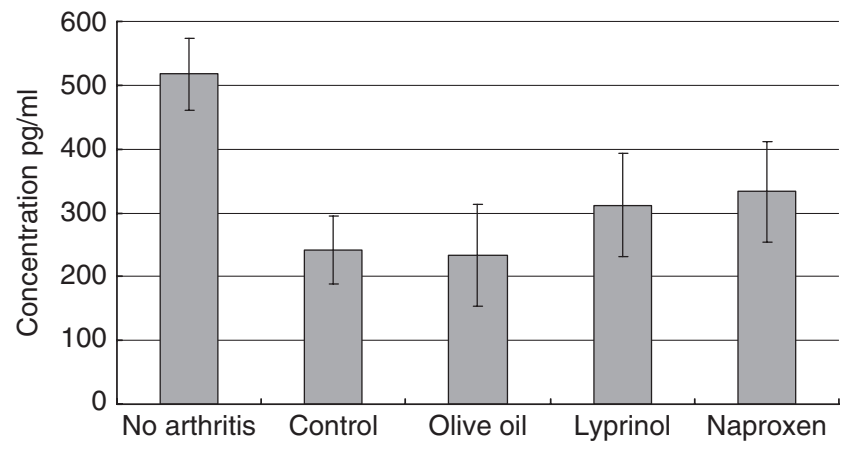

Figure 5. Amount of interleukin-10 (IL-10) produced by LPS-stimulated splenocytes after 28 days of arthritis induction. Lyprinol ${ }^{\mathbb{R}}$ can increase the amount of IL-10 production, an anti-inflammatory cytokine, although the difference was not statistically significant. Values shown are mean $\pm \operatorname{SEM}(n=6)$.

of mechanisms resulting in AI effects of the lipid extract of $P$. canaliculus, the green-lipped mussel from New Zealand $\left(\right.$ Lyprinol $\left.{ }^{\circledR}\right)$. A number of studies have been reported and/or published on this product in terms of its composition, its effects when compared with other drugs or lipids of diverse origins, its efficacy in several animal models and its effects on symptoms of OA and asthma.

Since the major complaint of patients suffering from acute exacerbations of chronic inflammatory disease is pain, we evaluated the analgesic effect of the lipid extract in the AIA rat model. We also measured levels of proinflammatory and anti-inflammatory cytokines. We compared results observed of Lyprinol, with a sham group (no drugs), an olive oil group (negative control), a non-steroid AI drug (NSAID) and a Naproxen (positive control) group. We also observed a group of rats as reference that were not treated with adjuvant.

Recent studies on pain, both in humans (33-36) and animals $(34,37,38)$ have demonstrated the active role of IL-6 in inducing pain, as well as IL-1 $\beta$, IL-8, TNF- $\alpha$ (TNF-R1 receptor) and IFN- $\gamma$. Conversely, IL-10 is associated with control of pain.

Lyprinol $^{\circledR}$ exhibits a significant effect controlling pain in several recent clinical studies. The group at the University of Hong Kong (8) conducted the first randomized controlled trial to evaluate the effects of Lyprinol $^{\circledR}$, on signs and symptoms and quality of life (QOL) of patients with knee OA. Their results showed that Lyprinol ${ }^{\circledR}$ over 6 months in patients with knee OA is perfectly tolerated and associated with a decrease in pain perception after 2 months when compared to placebo. The visual analog scale (VAS) for pain score was significantly reduced from 63.0 at baseline to 55.5 at Week $4(P=0.046), 51.2$ at Week $8(P=0.003)$ and 49.7 at Week $12(P=0.001)$. There was a greater significant reduction in VAS pain score following adjustment for change in amounts of paracetamol (acetaminophen) used in patients who received the lipid extract when compared with controls at Week 8
$(P=0.035), \quad$ Week $12 \quad(P=0.032) \quad$ and $\quad$ Week 24 $(P=0.045)$.

Another multi-center clinical study in Korea on patients with OA of the hip and knee found that the average VAS score, Lequesne functional index, global assessment by patients and global assessment by physician were all significantly improved (7). After a 4- and 8-week treatment period, $53-80 \%$ of patients experienced significant pain relief, and improvement of joint function. There was no reported adverse effect during this clinical trial (7).

A third study was conducted in Germany on 50 adults with inflammatory rheumatoid arthritis (21). The number of painful joints was reduced from $4.18 \pm 2.80$ at baseline by $0.30 \pm 0.81$ points $(7.2 \%)$ after 6 weeks and $0.60 \pm 1.18$ points $(14.4 \%)$ after 12 weeks $(P=0.012$ and $P=0.001)$. For a sub-parameter 'number of painful small joints', a highly significant reduction of $9.3 \%$ after 6 weeks and $18.6 \%$ after 12 weeks was observed $(P=0.022$ and $P=0.002)$. Analgesic medications were reduced or stopped in 21 subjects who required these at the beginning of the trial.

Our study of the mean pain score measurement by ten flexions of the tarsotibial joints of adjuvant-injected paw $(n=6)$ did demonstrate a significant reduction of pain in AIA rats treated with Lyprinol ${ }^{\circledR}$, or Naproxen. However, this reduction differed according to the product used to treat the rats: pain scores in Naproxen and Lyprinol ${ }^{\circledR}$ groups initially increased; but they decreased significantly and gradually in the Lyprinol ${ }^{\circledR}$ group to reach a nadir $($ score $=2)$ at Day 8 , while rats in the Naproxen group experienced a more erratic pain reduction with a significant nadir $($ score $=0$ ) at Day 9. However, the pain score started differing significantly after Day 9: the Lyprinol ${ }^{\circledR}$ group experienced a progressive increase in pain scores, reaching its initial level at Day 15; while the Naproxen group remained essentially pain-free during the rest (total days $=26)$ of the experiment. This curve, transposed to the human time scale, is quasi-identical to the pain scale observed by Lau et al. (8) where the maximum reduction in pain was observed after approximately $8-12$ weeks of treatment in patients with OA. It may well be due to an 'escape' mechanism from the production of pro-inflammatory cytokines that tend to increase despite treatment with Lyprinol $^{\circledR}$; it may also be due to other inflammatory mechanisms of AIA (and/or OA).

The cause of pain severity was confirmed by aspects of the inflamed paw when compared with the non-injected one, and comparative radiological images. X-rays confirmed the presence of major osteo-cartilaginous destruction as well as major swelling of the affected paw.

Pro-inflammatory cytokine production (TNF- $\alpha$, IFN- $\gamma$ ) was significantly controlled by Lyprinol ${ }^{\circledR}$ (Day 14), as well if not better than Naproxen. IL-10, an 'anti-inflammatory' cytokine was increased in the Lyprinol ${ }^{\circledR}$ and in the Naproxen group, but did not reach statistical significance. Extra-virgin olive oil was ineffective in our study. 
More importantly, after 1 year, rats that were treated with Lyprinol ${ }^{\circledR}$ had a normal AIA paw, while untreated rats had severe inflammatory, ulcerative lesions.

\section{Conclusion}

The lipid extract of $P$. canaliculus is known as a powerful AI product in animal models and human diseases (asthma, arthritis). We have confirmed in the adjuvantinduced arthritis rat model, that this product (Lyprinol ${ }^{\circledR}$ ) is an analgesic, as active as Naproxen during the early phase of treatment. AIA is a loco-regional highly inflammatory experimental condition, with systemic repercussions. Lyprinol ${ }^{\circledR}$ also controls as well as Naproxen the levels of pro-inflammatory cytokines $(\mathrm{TNF}-\alpha, \mathrm{IFN}-\gamma)$ in AIA rats; it increases the production of the AI cytokine IL-10 in AIA rats. Lyprinol ${ }^{\circledR}$ was perfectly tolerated, and AIA rats treated with Lyprinol ${ }^{\circledR}$ were lesion-free after 1 year, while untreated controls had major inflammatory, ulcerative lesions. The lipid extract of $P$. canaliculus seems to be uniquely safe and effective in the treatment of pain, both spontaneous (due to inflammation) and triggered by torsion of the affected joint, in AIA in rats.

\section{Acknowledgements}

Prof. Georges M. Halpern (MD, PhD) initiated this study; organized it and helped to shape the manuscript. $\mathrm{He}$ should have been the leading author. We thank Pharmalink International Company Ltd, Burleigh Heads, QLD, Australia, for supplying the lipid extract of P. canaliculus $\left(\right.$ Lyprinol $^{\circledR}$ ) and the placebo, and for an unrestricted educational and research grant that supported our study in part.

\section{References}

1. Gibson RG, Gibson SLM, Conway V, Chappell D. Perna canaliculus in the treatment of arthritis. Practitioner 1980;224:95560 .

2. Speed A, Zwar D. Introducing: the Ocean mussel that packs a punch against arthritis pain. Bio/Tech News 1997.

3. Whitehouse MW, Macrides TA, Kalafatis N. Anti-inflammatory activity of a lipid fraction $\left(\right.$ Lyprinol $^{\circledR}$ ) from the N. Z. green-lipped mussel. Inflammopharmacology 1997;5:237-46.

4. Gibson SLM, Gibson RG. The treatment of arthritis with a lipid extract of Perna canaliculus: a randomized trial. Complement Ther Med 1998;6:122-6.

5. Halpern GM. Anti-inflammatory effects of a stabilized lipid extract of Perna canaliculus (Lyprinol ${ }^{\circledR}$ ). Allergie Immunol (Paris) 2000;32:272-8.

6. Shiels IA, Whitehouse MW. Lyprinol $^{\mathbb{R}}$ : anti-inflammatory and uterine relaxant activities in rats, with special reference to a model for dysmenorrhea. Allergie Immunol (Paris) 2000;32:279-83.

7. Cho SH, Jung YB, Seong SC, Park HB, Byun KY, Lee DC, et al. Clinical efficacy and safety of Lyprinol, a patented extract from New Zealand green-lipped mussel (Perna canaliculus) in patients with osteoarthritis of the hip and knee: a multicenter 2-month clinical trial. Allergie Immunol (Paris) 2003;35:212-6.

8. Lau CS, Chiu PKY, Chu EMY, Cheng IYW, Tang WM, Man RYK, et al. Treatment of knee osteoarthritis with
Lyprinol $^{\circledR}$, lipid extract of the green-lipped mussel -a double-blind placebo-controlled study. Prog Nutrition 2004;6:17-31.

9. Tenikoff D, Murphy KJ, Le M, Butler RN, Howarth GS, Howe PR. Lyprinol ${ }^{\mathrm{TM}}$ : a potential preventive treatment for inflammatory bowel disease (IBD). Asia Pac J Clin Nutr 2004;13 (Suppl): S94.

10. Halpern GM. The Inflammation Revolution. Garden City, NY, USA: Square One Publishers, 2005.

11. Tenikoff D, Murphy KJ, Le M, Howe PR, Howarth GS. Lyprinol ${ }^{\circledR}$ (stabilized lipid extract of New Zealand green-lipped mussel): a potential preventative treatment modality for inflammatory bowel disease. J Gastroenterol 2005;40:361-5.

12. Cooper EL. Bioprospecting a CAM frontier. Evid Based Complement Alternat Med 2005;2:1-3.

13. Balamurugan M, Parthasarathi K, Cooper EL, Ranganathan LS. Earthworm paste (Lampito mauritii, Kinberg) alters inflammatory, oxidative, haematological and serum biochemical indices of inflamed rat. Eur Rev Med Pharmacol Sci 2007;11:77-90.

14. Prakash M, Balamurugan M, Parthasarathi K, Gunasekaran G, Cooper EL, Ranganathan LS. Anti-ulceral and anti-oxidative properties of "earthworm paste" of Lampito mauritii (Kinberg) on Rattus norvegicus. Eur Rev Med Pharmacol Sci 2007;11:9-15.

15. Suzuki KM, Isohama Y, Maruyama H, Yamada Y, Narita Y, Ohta $\mathrm{S}$, et al. Estrogenic activities of fatty acids and a sterol isolated from royal jelly. Evid Based Complement Alternat Med. doi:10.1093/ecam/ nem036.

16. Nigam Y, Bexfield A, Thomas S, Ratcliffe NA. Maggot therapy: the science and implication for CAM Part I-history and bacterial resistance. Evid Based Complement Alternat Med 2006;3:223-7.

17. Nigam Y, Bexfield A, Thomas S, Ratcliffe NA. Maggot therapy: the science and implication for CAM Part II-maggots combat infection. Evid Based Complement Alternat Med 2006;3:303-8.

18. Murphy KJ, Mooney BD, Mann NJ, Nichols PD, Sinclair AJ. Lipid, FA, and sterol composition of New Zealand green-lipped mussel (Perna canaliculus) and Tasmanian blue mussel (Mytilus edulis). Lipids 2002;37:587-95.

19. Wolyniak CJ, Brenna T, Murphy KJ, Sinclair AJ. Gas chromatography-chemical ionization-mass spectrometric fatty acid analysis of a commercial supercritical carbon dioxide lipid extract from New Zealand green-lipped mussel (Perna canaliculus). Lipids 2005;40:355-60.

20. Dugas B. Lyprinol inhibits $\mathrm{LTB}_{4}$ production by human monocytes. Allergie Immunol (Paris) 2000;32:284-9.

21. Gruenwald J, Graubaum HJ, Hansen K, Grube B. Efficacy and tolerability of a combination of Lyprinol and high concentrations of EPA and DHA in inflammatory rheumatoid disorders. Adv Ther 2004;21:197-201.

22. Emelyanov A, Fedoseev G, Krasnoschekova O, Abulimity A, Trendeleva T, Barnes PJ. Treatment of asthma with lipid extract of New Zealand green-lipped mussel: a randomised clinical trial. Eur Respir J 2002;20:596-600.

23. Murphy KJ, Mann NJ, Sinclair AJ. Fatty acid and sterol composition of frozen and freeze-dried New Zealand Green Lipped Mussel (Perna canaliculus) from three sites in New Zealand. Asia Pac J Clin Nutr 2003;12:50-60.

24. Kang SS, Choi SH. Prophylactic effect of plaster and cataplasm contained ketoprofen in rats with adjuvant arthritis. $J$ Vet Sci 2001;20:65-70.

25. Winder CV, Lembke LA, Stephens MD. Comparative bioassay of drugs in adjuvant-induced arthritis in rats: flufenamic acid, mefenamic acid, and phenylbutazone. Arthritis Rheum $1969 ; 12: 472-82$.

26. Hayashida K, Kaneko T, Takeuchi T, Shimizu H, Ando K, Harada E. Oral administration of lactoferrin inhibits inflammation and nociception in rat adjuvant-induced arthritis. J Vet Med Sci 2004;66:149-54.

27. Nakaya M, Yamasaki M, Miyazaki Y, Tachibana H, Yamada K. Estrogenic compounds suppressed interferon-gamma production in mouse splenocytes through direct cell-cell interaction. In Vitro Cell Dev Biol Anim 2003;39:383-7.

28. Zimecki M, Weber-Dabrowska B, Lusiak-Szelachowska M, Mulczyk M, Boratynski J, Pozniak G, et al. Bacteriophages provide 
regulatory signals in mitogen-induced murine splenocyte proliferation. Cell Mol Biol Lett 2003;8:699-711.

29. Wang Y, Huang C, Cao Y, Han JS. Repeated administration of low dose ketamine for the treatment of monoarthritic pain in the rat. Life Sci 2000;67:261-7.

30. Laird JM, Carter AJ, Grauert M, Cervero F. Analgesic activity of a novel use-dependent sodium channel blocker, crobenetine, in mono-arthritic rats. $\mathrm{Br} J$ Pharmacol 2001;134:1742-8.

31. Yu YC, Koo ST, Kim CH, Lyu Y, Grady JJ, Chung JM. Two variables that can be used as pain indices in experimental animal models of arthritis. J Neurosci Methods 2002;115:107-13.

32. Whitehouse MW. Adjuvant-induced polyarthritis in rats. In: Greenwald RA, Diamond HS (eds). CRC Handbook of Animal Models for the Rheumatic Diseases, Vol. 1, Miami, FL, USA: CRC Press, 1996.

33. Beilin B, Bessler H, Mayburd E, Smirnov G, Dekel A, Yardeni I, et al. Effects of preemptive analgesia on pain and cytokine production in the postoperative period. Anesthesiology 2003;98:151-5.

34. Milligan ED, Langer SJ, Sloane EM, He L, Wieseler-Frank J, O'Connor K, et al. Controlling pathological pain by adenovirally driven spinal production of the anti-inflammatory cytokine, interleukin-10. Eur J Neurosci 2005;21:2136-48.

35. Oen K, Malleson PN, Cabral DA, Rosenberg AM, Petty RE, Nickerson $P$, et al. Cytokine genotypes correlate with pain and radiologically defined joint damage in patients with juvenile rheumatoid arthritis. Rheumatology (Oxford) 2005:44:1115-21.

36. Wu CT, Jao SW, Borel CO, Yeh CC, Li CY, Lu CH, et al. The effect of epidural clonidine on perioperative cytokine response, postoperative pain, and bowel function in patients undergoing colorectal surgery. Anesth Analg 2004;99:502-9.

37. Sommer C. Animal studies on neuropathic pain: the role of cytokines and cytokine receptors in pathogenesis and therapy. Schmerz 1999;13:315-23.

38. Kwon MS, Shim EJ, Seo YJ, Choi SS, Lee JY, Lee HK, et al. Effect of aspirin and acetaminophen on pro-inflammatory cytokine-induced pain behavior in mice. Pharmacology 2005;74:152-156.

Received November 9, 2006; accepted July 10, 2007 


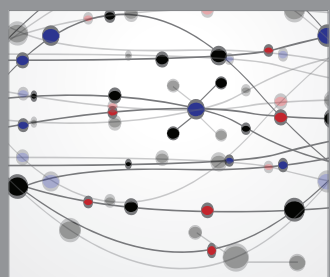

The Scientific World Journal
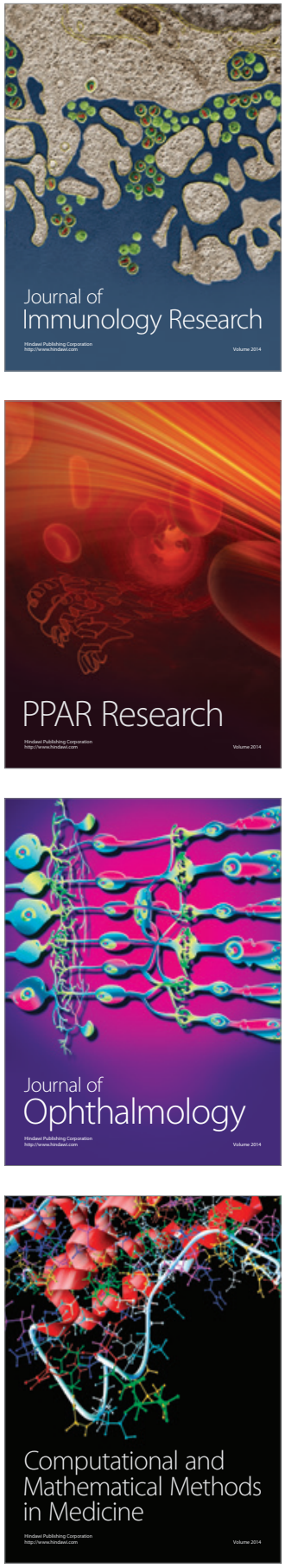

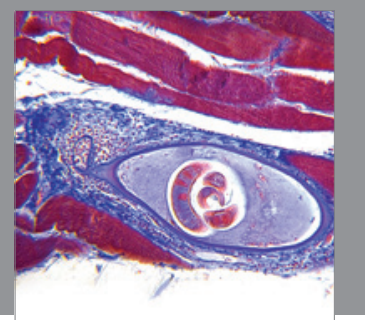

Gastroenterology

Research and Practice
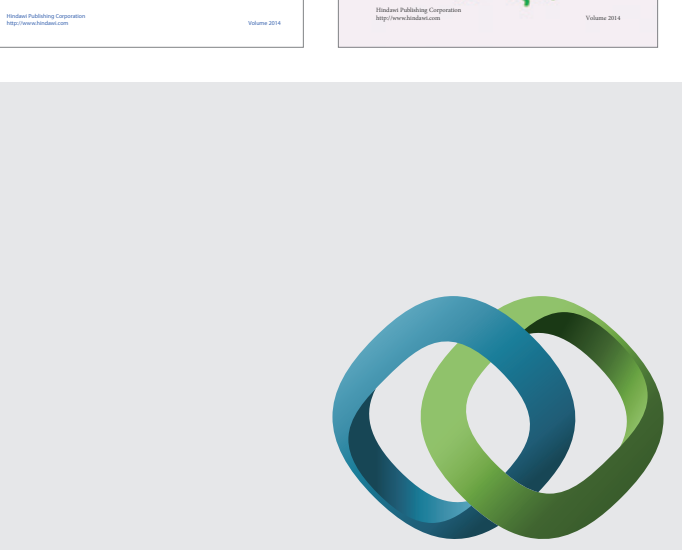

\section{Hindawi}

Submit your manuscripts at

http://www.hindawi.com
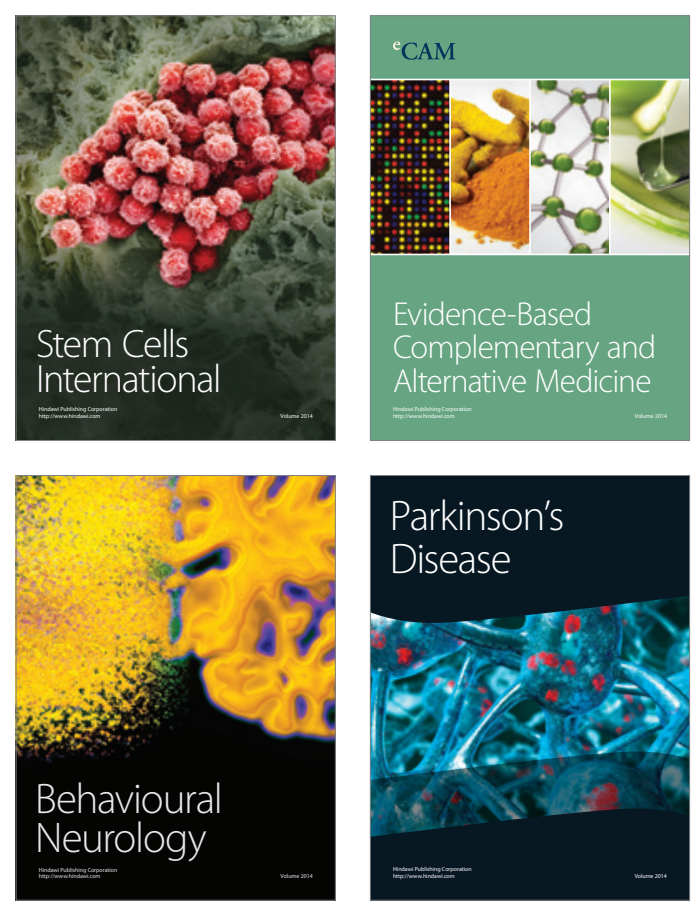

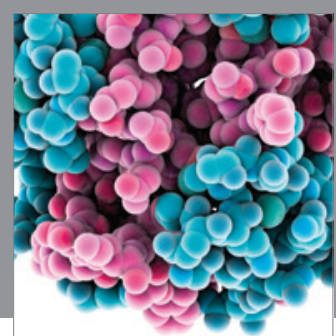

Journal of
Diabetes Research

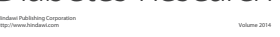

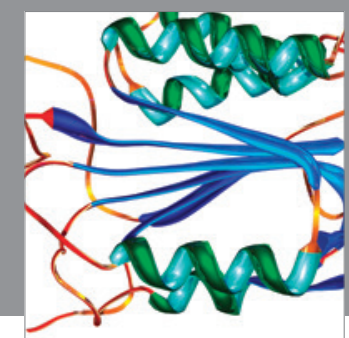

Disease Markers
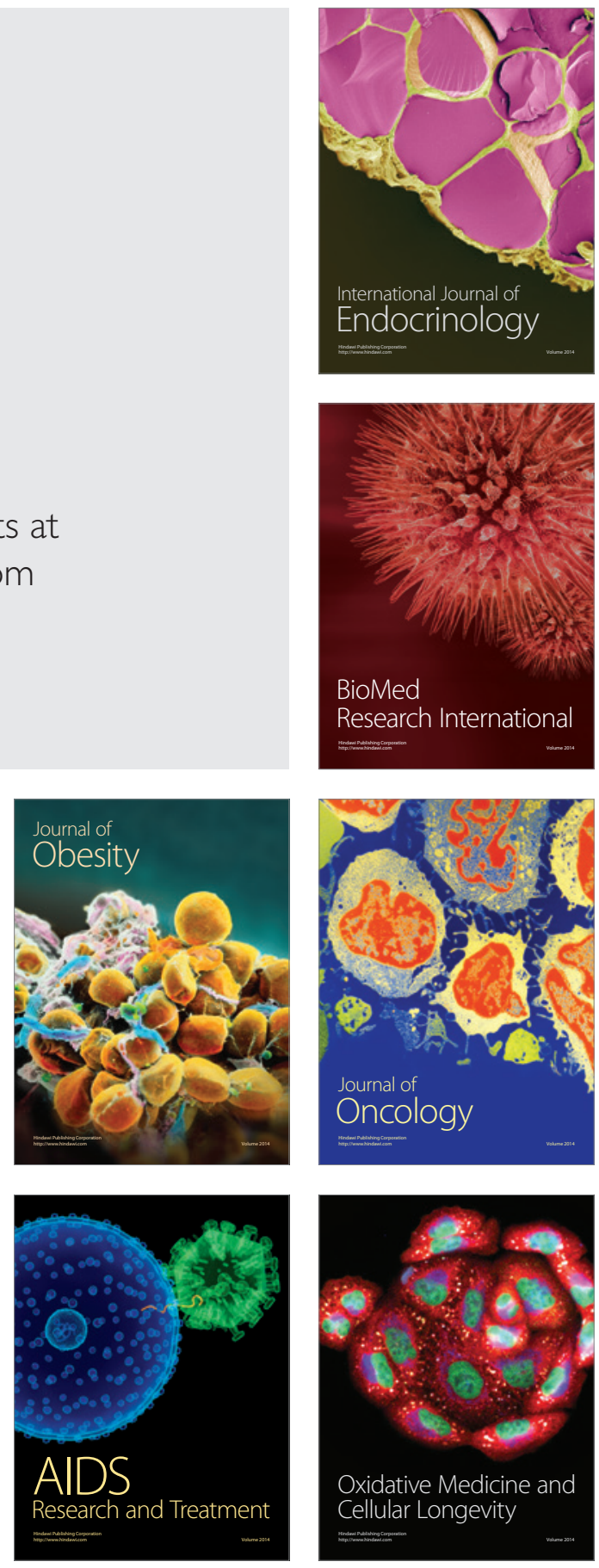